\title{
Effects of a Workplace-Smoking Ban in Combination With Tax Increases on Smoking in the Dutch Population
}

Citation for published version (APA):

Verdonk-Kleinjan, W. M. I., Candel, M. J. J. M., Knibbe, R. A., Willemsen, M. C., \& de Vries, H. (2011). Effects of a Workplace-Smoking Ban in Combination With Tax Increases on Smoking in the Dutch Population. Nicotine \& Tobacco Research, 13(6), 412-418. https://doi.org/10.1093/ntr/ntr014

Document status and date:

Published: 01/06/2011

DOI:

10.1093/ntr/ntr014

Document Version:

Publisher's PDF, also known as Version of record

Document license:

Taverne

Please check the document version of this publication:

- A submitted manuscript is the version of the article upon submission and before peer-review. There can be important differences between the submitted version and the official published version of record.

People interested in the research are advised to contact the author for the final version of the publication, or visit the DOI to the publisher's website.

- The final author version and the galley proof are versions of the publication after peer review.

- The final published version features the final layout of the paper including the volume, issue and page numbers.

Link to publication

\footnotetext{
General rights rights.

- You may freely distribute the URL identifying the publication in the public portal. please follow below link for the End User Agreement:

www.umlib.nl/taverne-license

Take down policy

If you believe that this document breaches copyright please contact us at:

repository@maastrichtuniversity.nl

providing details and we will investigate your claim.
}

Copyright and moral rights for the publications made accessible in the public portal are retained by the authors and/or other copyright owners and it is a condition of accessing publications that users recognise and abide by the legal requirements associated with these

- Users may download and print one copy of any publication from the public portal for the purpose of private study or research.

- You may not further distribute the material or use it for any profit-making activity or commercial gain

If the publication is distributed under the terms of Article $25 \mathrm{fa}$ of the Dutch Copyright Act, indicated by the "Taverne" license above, 


\title{
Original Investigation \\ Effects of a Workplace-Smoking Ban in Combination With Tax Increases on Smoking in the Dutch Population
}

\author{
Wendy M. I. Verdonk-Kleinjan, ${ }^{1}$ Math J. J. M. Candel, Ph.D., ${ }^{2}$ Ronald A. Knibbe, Ph.D., ${ }^{3}$ Marc C. Willemsen, Ph.D., ${ }^{4,5}$ \& \\ Hein de Vries, Ph.D. ${ }^{3}$ \\ ${ }^{1}$ Food and Consumer Product Safety Authority (FCPSA), Eindhoven, The Netherlands \\ ${ }^{2}$ Department of Methodology and Statistics, Faculty of Health, Medicine and Life Science, University Maastricht, Maastricht, The Netherlands \\ ${ }^{3}$ Department of Health Education and Promotion, Faculty of Health, Medicine and Life Science, University Maastricht, Maastricht, \\ The Netherlands \\ ${ }^{4}$ Dutch Expertise Centre on Tobacco Control, STIVORO, The Hague, The Netherlands \\ ${ }^{5}$ Department of Health Education and Promotion, CAPHRI, Maastricht, The Netherlands
}

Corresponding Author: Wendy M. I. Verdonk-Kleinjan, Directorate Implementation Enforcement and Surveillance, Food and Consumer Product Safety Authority (VWA), PO Box 2168, 5600 CD Eindhoven, The Netherlands. Telephone +31-0-40-2911500; Fax +31-0-40-2911600; E-mail:wendy.verdonk-kleinjan@vwa.nl

Received June 7, 2010; accepted January 14, 2011

\section{Abstract}

Introduction: In the Netherlands, between 2003 and 2005, 3 tobacco control measures were implemented: a workplacesmoking ban and 2 tax increases on tobacco products. This study explores how the combination of measures influences the smoking behavior of the general population divided into subpopulations with and without paid work (all aged 16-65 years).

Methods: Data from the Dutch Continuous Survey of Smoking Habits were used. The total sample consisted of 32,014 respondents $(27,150$ with paid work and 4,864 without paid work) aged 16-65 years. Analyses were done by linear and logistic regression, controlling for relevant factors.

Results: For respondents with paid work, the combination of a smoking ban and 2 tax increases led to a decrease in the number of cigarettes per day and in the prevalence of daily smoking. For respondents without paid work, there was no significant effect on any of the outcome parameters. In both groups, there was no evidence that the effect of the measures on smoking was moderated by the respondent's gender, age, or level of education.

Conclusions: The combination of policy measures has influenced the smoking behavior of respondents with paid work in a positive way. Compared with most other studies, the effect of the workplace-smoking ban alone is smaller. However, the effect of the combined interventions is higher than the that of tax increases in other studies. Among respondents without paid work who were exposed to tax increases only, no significant effects were found.

\section{Introduction}

In 1996, the Netherlands introduced a tobacco discouragement policy in line with the World Health Organization (WHO)
Framework Convention on Tobacco Control. Most of the measures related to this policy were implemented after 2002, that is, a youth access law (2003), an advertising ban (2002), and textual health warnings on cigarette packages (2002). In January 2004, a workplace-smoking ban (from which the hospitality industry was exempt) came into action. One month later, in February 2004 , the taxes on tobacco increased by $20 \%$. In January 2005, an additional tax was implemented related to minimum prices of tobacco products, which increased prices by (about) another $4 \%$.

The present study evaluates the impact of the combination of the workplace-smoking ban and the two tax increases on the smoking behavior of the general population (aged 16-65 years). Subpopulations of those with and without paid work were examined as these two groups differ in their level of exposure to the workplace-smoking ban.

It is generally assumed that a combination of measures has more effect than each of the separate measures (Joossens \& Raw, 2006; Levy, Chaloupka, \& Gitchell, 2004; Pierce \& León, 2008). Three studies (Emont, Choi, Novotny, \& Giovino, 1993; Stephens, Pederson, Koval, \& Kim, 1997; Stephens, Pederson, Koval, \& Macnab, 2001) investigated the impact of the combination of no-smoking laws and increased taxation, but none differentiated the effects for relevant subpopulations. Studies on the impact of a workplace-smoking ban in various countries revealed a decline in the daily cigarette consumption and a reduction in smoking prevalence among working people and in the general population (Brownson, Eriksen, Davis, \& Warner, 1997; Chapman et al., 1999; Fichtenberg \& Glantz, 2002; Heloma \& Jaakkola, 2003; Hopkins et al., 2001; Joossens \& Raw, 2006; Levy et al., 2004). The effect of tax increases is mostly reported in terms of price elasticity. A $10 \%$ increase in price is associated with a $4 \%$ reduction in tobacco consumption (daily

doi: $10.1093 / n t r / n t r 014$

Advance Access published on February 28, 2011

(C) The Author 2011. Published by Oxford University Press on behalf of the Society for Research on Nicotine and Tobacco.

All rights reserved. For permissions, please e-mail: journals.permissions@oup.com 
cigarette consumption and smoking prevalence; Fichtenberg \& Glantz, 2002 ; Guindon, Tobin, \& Yach, 2002; Hopkins et al., 2001; Joossens \& Raw, 2006).

The present study examines the influence of both the workplace-smoking ban and tax increases on persons with paid work, whereas the effect of the tax increases alone was studied in those without paid work. The dataset used covers smoking behavior in the general population for 36 months. This specific study period covers implementation of the three measures and allows a more comprehensive examination of the cumulative effects of the measures (Figure 1). For both subpopulations, we expect to see a decline in the intensity of smoking, an increase in quit attempts, and a decrease in the prevalence of smoking. Since the effect of both measures may differ according to age, gender, education (Farrelly, Evans, \& Sfekas, 1999; Hopkins et al., 2001; Joossens \& Raw, 2006; Levy, Romano, \& Mumford, 2005; Levy et al., 2004; Thomas et al., 2008; Townsend, Roderick, \& Cooper, 1994), and working hours (Evans, Farrelly, \& Montgomery, 1999), these variables were included as moderators. Furthermore, since one of the intervention periods is close to New Year, we also control for possible confounding due to the "New Year" effect, that is, taking into account the large number of smokers who start the New Year with an attempt to stop smoking.

\section{Methods}

\section{Study Design and Setting}

The Continuous Survey of Smoking Habits (CSSH) has continuously monitored smoking behavior in the Dutch population since 1976. Each week, 200 respondents are randomly selected from a database of more than 200,000 respondents representative for the Dutch population aged 15 years and older. To ensure representativeness, the sample is weighted for region, urbanization, gender, age, household composition, and level of education. The subjects were approached by Internet to fill in a questionnaire.

For the present study, data collected in 2003, 2004, and 2005 were used from which we selected all 32,014 respondents aged 16-65 years. Figure 1 shows the timeline of the interventions. Respondents with paid work were exposed to the following interventions: the workplace-smoking ban from January 1, 2004 to February 1, $2004(n=601)$, the workplace-smoking ban and the first tax increase from February 1, 2004 to January 1, 2005 ( $n=8,427)$, and the workplace-smoking ban and the first and second tax increase from January 1, 2005 to December 31, 2005 $(n=8,908)$. Those without paid work were not exposed to an intervention until February $2004(n=1,825)$; they were exposed to the first tax increase from February 1, 2004 to January 1, 2005 ( $n=1,521)$ and to the first and second tax increases from January 1, 2005 to December 31, $2005(n=1,518)$.

\section{Characteristics of the Participants}

Table 1 presents the main sociodemographic characteristics of those with and without paid work. There were significant $(p<.001)$ differences in gender, age, and level of education when we compared the group of the respondents with paid work with that without paid work.

\section{Measurements}

Whether respondents had paid work was assessed by verifying whether their income was derived from paid employment. The outcome measures were intensity of smoking, whether a person made a quit attempt last month, and whether a person was a daily smoker. The intensity of smoking was measured by the number of cigarettes per day per smoker. Smoking prevalence was calculated as the percentage of respondents who smoked daily. The variables gender (male and female), age (16-29, 3049, and 50-65 years), educational level (low, middle, and high), and number of hours with paid work per week (1-14 and $15 \mathrm{hr}$ or more) were measured with direct questions. The variable "New Year" effect was created by identifying the respondents interviewed in January 2003, 2004, and 2005. The various interventions are operationalized by making dummy variables for the different time intervals, each corresponding to a different set of interventions to which the respondents were exposed (Figure 1). For employees, we made three "time interval dummies": January 2004 (ban) and February 2004 till January 2005 (first tax increase) and 2005 (second tax increase). For non employees, we made two "time interval dummies": February 2004 till January 2005 (first tax increase) and 2005 (second tax increase).

\section{Statistical Analysis}

The analyses were stratified for those with $(n=27,150)$ and without $(n=4,864)$ paid work. These categories differ in the measures to which they were exposed as those not working could not have experienced the workplace-smoking ban. The design of the study implies that, in the period after the workplace-smoking ban, the "measures" are no longer comparable. For those who are working, the effects of the measure "first tax increase" are in fact the effects of a tax increase in combination with the workplace smoking ban, while for those without work, the effects represent the effects of the tax increase only.

\begin{tabular}{|c|c|c|c|}
\hline Year & 2003 & 2004 & 2005 \\
\hline Months & \begin{tabular}{lllllll|l|l|l} 
& 1 & 1 & 1 & 1 & 1 & 1 & 1 & 1 & 1
\end{tabular} & 111111111111 & 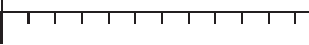 \\
\hline $\begin{array}{l}\text { Type of } \\
\text { Intervention }\end{array}$ & Workplace-smoking ban & Tax increase & Tax \\
\hline Paid work & No intervention & 1. and 2. & 1. 2. and 3. \\
\hline$(n=27,150)$ & $(n=9,214)$ & $(n=8,427)$ & $(n=8,908)$ \\
\hline No paid work & No intervention & 2. & 2. and 3. \\
\hline$(n=4,864)$ & $(n=1,825)$ & $(n=1,521)$ & $(n=1,518)$ \\
\hline
\end{tabular}

Figure 1. Respondents with and without paid work and exposure to interventions. 
Table 1. Characteristics of the Respondents (percentages)

\begin{tabular}{|c|c|c|}
\hline & \multirow{2}{*}{$\frac{\text { With paid work }}{n=27,150}$} & \multirow{2}{*}{$\begin{array}{l}\text { Without paid work } \\
n=4,864\end{array}$} \\
\hline & & \\
\hline \multicolumn{3}{|l|}{ Gender } \\
\hline Male & 54.7 & 12.3 \\
\hline Female & 45.3 & 87.7 \\
\hline \multicolumn{3}{|c|}{ Age group in years } \\
\hline $16-29$ & 19.6 & 24.1 \\
\hline $30-49$ & 59.5 & 38.1 \\
\hline $50-65$ & 20.8 & 37.8 \\
\hline \multicolumn{3}{|c|}{ Education level } \\
\hline Low & 31.5 & 52.5 \\
\hline Middle & 39.8 & 34.4 \\
\hline High & 28.7 & 13.1 \\
\hline
\end{tabular}

For the two categories of respondents, chi-square tests were used to assess differences between baseline and postintervention measurements in the proportion of respondents that reported to smoke daily and that reported a quit attempt. $t$-tests were used to assess differences between baseline and postintervention measurements in the number of cigarettes per smoker per day.

To check whether the analysis of the impact of the measures should be controlled for a variable capturing trends over time, we used the 2003 data. A linear regression (number of cigarettes) or logistic regression analysis (daily smoking and quit attempts) with the month of the year 2003 as independent variable and gender, age, education, and New Year as control variables was conducted to detect a possible trend over the 12 month of 2003. However, neither in the total population nor separately for those with and without paid work was a trend found for the smoking prevalence, the proportion of quitters, or the number of cigarettes smoked.

Multiple linear and logistic regression analyses were used to analyze the effect of the measures on, respectively, the number of cigarettes per day (among smokers), the proportion of quitters, and the proportion of daily smokers, controlling for gender, age, level of education and weekly working hours (only for those who worked), and the "New Year" effect. Each of the outcome measures were regressed on the variable type of intervention. For those with paid work, the measures were represented by three dummies (implementation of the ban, implementation of the ban and the first tax increase, and implementation of the ban and first and second tax increase). For those without paid work, two dummies (first tax increase and both the first and the second tax increase) were used. Furthermore, we tested for interaction effects between the various interventions and covariates (except for the "New Year" variable) on each of the outcome variables. We examined all regression analyses for multicollinearity by inspecting the variance inflation factors. The variance inflation factors were between 1.0 and 1.4, indicating no high multicollinearity. By calculating Cook's distance for each subject, all analyses were checked for influential observations. Whenever necessary, analyses were redone after deleting subjects with a Cook's distance larger than 1 .
For all analyses, a significance level of $p<.05$ was used. Data were analyzed using SPSS 15.0 for Windows.

\section{Results}

\section{Intensity of Smoking}

Among smokers with paid work, the average number of cigarettes decreased from 15.0 cigarettes/day before the interventions to 13.8 cigarettes/day $(p=.09)$ after implementation of the workplace-smoking ban and to 14.2 cigarettes/day $(p=.002)$ after the ban and the two tax increases. Among smokers without paid work, there were no significant changes in the number of cigarettes per day before the interventions (14.7) and after the two tax increases (14.9). If we combine the decrease in intensity of smoking with the decrease in prevalence of smoking after the ban and the two tax increases (see below), we estimate that the total cigarette consumption among the employed $(n=27,150)$ is reduced from 111,994 to 93,684 cigarettes/day, which is a $16.3 \%$ reduction in total cigarette consumption. For those without paid work $(n=4,864)$, we estimate a reduction from 15,158 to 14,495 cigarettes/day, which is a $4.4 \%$ reduction in total cigarette consumption.

Table 2 shows the results of the multiple linear regression analysis for smokers with and without paid work. For respondents with paid work, only the effect of the smoking ban was not significant. The effects of the first and second tax increases, implemented after the workplace-smoking ban, were significant. It is important to note that the number of respondents interviewed in the month during which the smoking ban only (without additional tax increases) was in force (i.e., January 2004) is much smaller than the number of respondents exposed to both the ban and the tax increase(s). This probably explains why, despite a relatively strong effect of the ban $(-1.28$ cigarettes per smoker per day), this effect is not significant, whereas the effects of both tax increases $(-0.53 ;-0.85)$ are significant. Furthermore, there were significant differences in the number of cigarettes smoked according to gender, age, and education. Women smoked less cigarettes than men $(-0.77)$, and the youngest age group (16-29 years) smoked less cigarettes compared with those aged 30-49 (-1.67) and 50-65 years (-3.34). Lower educated employees smoked more cigarettes than the middle (1.94) and higher educated employees (3.88). Analysis of interactions of the different interventions with the relevant factors showed no significant interaction, indicating that subpopulations did not differ in the effect of the interventions.

Among respondents without paid work, there were no significant effects of the tax increases on the number of cigarettes per smoker per day. Because the statistical power for those without paid work is much smaller, it is informative to examine the estimated effect sizes of the tax increases. It appears that these are estimated to be opposite and smaller than for those with work for the first ( 0.29 vs. -0.53$)$ and second (0.34 vs. -0.85$)$ tax increase. The effects of age and education are similar to the effects for those with paid work. Analysis of interactions of the two tax increases with the relevant covariates did not reveal any significant interactions. 


\begin{tabular}{|c|c|c|}
\hline Variable & $\begin{array}{l}\text { Paid work, } \beta \\
(95 \% C I), \mathrm{n}=7,334\end{array}$ & $\begin{array}{l}\text { Without paid work, } \\
\beta(95 \% C I), \mathrm{n}=1,018\end{array}$ \\
\hline Constant & $14.65(13.69-15.61)$ & $13.09(11.18-14.99)$ \\
\hline Intervention $(0=$ no interventions $/ 1=$ the ban $)$ & $-1.28(-2.82$ to 0.26$)$ n.s. & - \\
\hline Intervention $(0=$ no interventions $/ 1=$ the ban and first tax increase $)$ & $-0.53(-1.04 \text { to }-0.03)^{*}$ & - \\
\hline Intervention $(0=$ no interventions $/ 1=$ the ban and two tax increases $)$ & $-0.85(-1.33 \text { to }-0.37)^{\star *}$ & - \\
\hline Intervention $(0=$ no interventions $/ 1=$ first tax increase $)$ & - & $0.29(-1.12$ to 1.70$)$ n.s. \\
\hline Intervention $(0=$ no interventions $/ 1=$ two tax increases $)$ & - & $0.34(-0.94$ to 1.62$)$ n.s \\
\hline "New year variable" $(0=$ other months $/ 1=$ month January $)$ & -0.12 ( -0.69 to 0.93$)$ n.s. & $\begin{array}{l}-1.08(-3.04 \text { to } 0.89) \\
\text { n.s. }\end{array}$ \\
\hline Gender $(0=$ male $/ 1=$ female $)$ & $-0.77(--1.19 \text { to }-0.35)^{* * *}$ & $0.52(-1.29-2.34)$ n.s. \\
\hline Age group in years $(0=16-29 / 1=30-49 / 2=50-65)$ & $1.67(1.33-2.00)^{* * *}$ & $2.05(1.22-2.88)^{\star * *}$ \\
\hline Education $(0=$ low $/ 1=$ middle $/ 2=$ high $)$ & $-1.94(-2.22 \text { to }-1.67)^{\star * *}$ & $-2.19(-3.11-1.27)^{\star \star \star}$ \\
\hline Hours paid work per week $(0=1-14 \mathrm{hr} / 1=\geq 15 \mathrm{hr})$ & $\begin{array}{l}0.65(-0.15 \text { to } 0.93) \text { n.s. } \\
\text { F-overall } 49.25^{\star * *}\end{array}$ & $\begin{array}{l}- \\
F \text {-overall } 11.75^{\star * *}\end{array}$ \\
\hline
\end{tabular}

Note. n.s. $=$ nonsignificant.

${ }^{\star} p<.05 ;{ }^{* *} p<.01 ;{ }^{* *} p<.001$.

\section{Quit Attempts}

Among those with and without paid work, there were no significant changes in the percentage of quit attempts. Among those with paid work, the percentage of smokers who made an attempt to quit was $1.0 \%$ in the period before the ban and tax increases and $1.2 \%$ afterward. In the short period after the implementation of the ban but before the tax increases (i.e., January 2004), the percentage of smokers trying to quit was significantly larger: $5.0 \%(p<.001)$. Among those without paid work, the percentage of smokers making an attempt to quit was $1.3 \%$ before and $0.3 \%$ after both tax increases.

The results of logistic regression analyses showed an acceptable fit of the model to the data: The Hosmer and Lemeshow tests for those with and without paid work were, respectively, $\chi^{2}$ $(d f=8)=2.725(p=.95)$ and $\chi^{2}(d f=8)=2.943(p=.94)$. When controlling for the covariates, the effects of the interventions were not significant among those with or without paid work. For those with paid work, associations were found between quit attempts and the period after New Year, number of working hours, and age. Smokers were more likely to attempt to quit smoking in the month after New Year (odds ratio $[O R]: 2.67$ ). This explains the relatively high percentage of quitters as reported above in the univariate analysis for January 2004. Smokers working more than $15 \mathrm{hr}$ a week were less likely to quit smoking (OR: 0.45), and older smokers were also less likely to quit smoking (OR: 0.69). There were no significant differences in quit attempts according to gender or education. Analysis of interaction effects did not reveal any significant interaction.

Among those without paid work, none of the covariates were significantly associated with attempts to quit. Removal of a subject without paid work having a Cook's distance clearly larger than 1 yielded very similar results.

\section{Prevalence of Smoking}

Among those with paid work, the percentage of daily smokers decreased from $27.5 \%$ before implementation of the ban and both tax increases to $25.5 \%$ (nonsignificant) after implementation of the ban and to $24.3 \%(p<.001)$ after all interventions. Among those without paid work, the proportion of daily smokers showed no significant change after the interventions: Before the interventions, $21.2 \%$ were daily smokers compared with $20.0 \%$ after the tax increases. If we examine the prevalence of incidental smokers, we find no significant changes. Among those with paid work, the percentage of incidental smokers was 5.6\% (before the ban), 6.0\% (after the ban), and 5.6\% (after both tax increases). Among those without paid work, we found a nonsignificant decrease from $3.5 \%$ before the tax increases to $2.5 \%$ after both tax increases.

We conducted multiple logistic regression to establish the effect of the different interventions on daily smoking for those with and without paid work. The analysis models showed a reasonable fit to the data for those with paid work but less for those without paid work. Hosmer and Lemeshow tests for those with and without paid work were, respectively, $\chi^{2}(d f=8)=13.994$ $(p=.82)$ and $\chi^{2}(d f=8)=41.015(p<.01)$. All Cook's distances, however, were clearly smaller that 1 . Table 3 shows that for paid workers, there was no significant change (OR: 0.87) in the likelihood of daily smoking among the respondents interviewed in the one month (January 2004) in which the ban without additional tax increases was in force, although the $O R$ was similar to the other interventions. The effects of the first (OR: 0.86) and second tax increase (OR: 0.85) after the ban on daily smoking were significant and in the expected direction. Gender, age, education, and hours of paid work per week are related to daily smoking. The likelihood of daily smoking was lower among females (OR: 0.88), among the older age groups compared with the younger age groups (OR: 0.87 ), and among the higher educated group compared with the lower educated group (OR: 0.59). For those with more than $15 \mathrm{hr}$ a week paid work, a higher likelihood (OR: 1.34) was found. No significant interactions were found between the different interventions and the covariates, indicating no differences in intervention effects between the paid workers. 


\begin{tabular}{|c|c|c|}
\hline Variable & $\begin{array}{l}\text { Paid work, OR } \\
(95 \% C I), n=27,067\end{array}$ & $\begin{array}{l}\text { Without paid work, } \\
\text { OR }(95 \% \text { CI }), n=4,840\end{array}$ \\
\hline Intervention $(0=$ no interventions $/ 1=$ the ban $)$ & $0.87(0.70-1.08)$ n.s. & - \\
\hline Intervention $(0=$ no interventions $/ 1=$ the ban and first tax increase $)$ & $0.86(0.80-0.92)^{\star * *}$ & - \\
\hline Intervention $(0=$ no interventions $/ 1=$ the ban and two tax increases $)$ & $0.85(0.80-0.91)^{\star * *}$ & - \\
\hline Intervention $(0=$ no interventions $/ 1=$ first tax increase $)$ & - & $0.87(0.73-1.04)$ n.s. \\
\hline Intervention $(0=$ no interventions $/ 1=$ two tax increases $)$ & - & $0.94(0.79-1.12)$ n.s. \\
\hline "New year variable" ( $0=$ other months $1=$ month January $)$ & $1.04(0.93-1.17)$ n.s. & $0.93(0.71-1.20)$ n.s. \\
\hline Gender $(0=$ male $/ 1=$ female $)$ & $0.88(0.83-0.93)^{\star * *}$ & $1.11(0.86-1.42)$ n.s. \\
\hline Age group in years $(0=16-29 / 1=30-49 / 2=50-65)$ & $0.87(0.85-0.93)^{* * *}$ & $0.84(0.75-0.93)^{\star *}$ \\
\hline Education $(0=$ low $/ 1=$ middle $/ 2=$ high $)$ & $0.59(0.57-0.61)^{\star * \star}$ & $0.54(0.48-0.61)^{* * *}$ \\
\hline Hours paid work per week $(0=1-14 \mathrm{hr} / 1=\geq 15 \mathrm{hr})$ & $1.34(1.20-1.49)^{\star * *}$ & - \\
\hline & $-2 \log$ likelihood ratio $879.616^{* * *}$ & $-2 \log$ likelihood ratio $114.057^{\star \star *}$ \\
\hline
\end{tabular}

Note. n.s. $=$ nonsignificant; $O R=$ odds ratio.

${ }^{*} p<.05 ;{ }^{* *} p<.01 ;{ }^{* *} p<.001$.

Among those without paid work, the tax increases had no significant effect on the likelihood of daily smoking. However, in terms of effect size, there was little difference between those with and without paid work in the effect of the first (OR: 0.86 vs. OR: 0.87$)$ and second (OR: 0.85 vs. OR: 0.94$)$ tax increase. For the other factors, the likelihood of daily smoking was related to age and education. Older and higher educated respondents were less likely to be daily smokers (OR: 0.84 and OR: 0.54, respectively). Analysis of interactions showed no significant intervention effects.

\section{Discussion}

The combination of government policies was expected to influence tobacco smoking. For those with paid work, the workplace-smoking ban and the two tax increases indeed resulted in a decrease in the number of cigarettes smoked per day and in the prevalence of daily smoking. There were no changes in the prevalence of incidental smoking among workers with or without paid work. For those without work, no significant effect of the tax increases was found. For both groups, no interaction effects between the interventions on the one hand and gender, age, level of education, and working hours on the other were found.

We first discuss the findings related to the influence of the workplace-smoking ban and then discuss the influence of tax increases.

One could argue that because the effect of the smoking ban alone was not significant, the workplace-smoking ban had no influence on respondents with paid work. However, the very short period (only 1 month) in which only the smoking ban was in force implies that very few respondents were available to evaluate the effect of this single measure. If we also consider the effect size, it appears that the $O R$ for the smoking ban for daily smoking (0.87) was comparable to that for the tax increases (0.86 and 0.85$)$. The effect of the workplace-smoking ban on smoking intensity $(-1.28)$ is estimated to have more than twice the effect of the first tax increase $(-0.53)$. The effect sizes indi- cate that the nonsignificance may have been due to the lack of statistical power. Moreover, one can safely assume that the effect of the workplace-smoking ban lasts longer than the one month during which it was the sole measure implemented. Therefore, the influence of the workplace-smoking ban is likely to be incorporated in the effects found for the first and second tax increase.

Although the lack of significance for the workplace-smoking ban may be due to too low statistical power, the effect size of the workplace-smoking ban is smaller than effect sizes found in other studies reporting on a workplace-smoking ban only. Review studies on workplace-smoking ban report a reduction in the number of cigarettes per day ranging from 3.5 (Chapman et al., 1999) or 3.2 (Fichtenberg \& Glantz, 2002) to 1.2 cigarettes (Hopkins et al., 2001). A recent WHO study and European studies reported a decrease in cigarette use of 2-4 cigarettes/day and concluded that there is strong evidence that smoke-free workplaces decrease the prevalence of smoking (Pierce \& León, 2008; International Agency for Research on Cancer, 2009). These are larger reductions than we found for the workplacesmoking ban (1.2 cigarettes/day). Similarly, the reduction in prevalence of the daily smoking (2.0 percentage points) after the smoking ban is smaller compared with reductions reported for a workplace-smoking ban only in review studies: 5 percentage points (Brownson et al., 1997), 5-5.6 percentage points (Chapman et al., 1999), 3.8 percentage points (Fichtenberg \& Glantz, 2002), and 1.4-11.4 percentage points (Hopkins et al., 2001). Most studies on the effect of a workplace-smoking ban had a follow-up of up to one year (Brownson et al., 1997; Fichtenberg \& Glantz, 2002). Studies with a longer follow-up show mixed results. During a 4-year follow-up, Heloma \& Jaakkola (2003) found that the effect increased over time, Fichtenberg \& Glantz (2002) found in their review that the effects remained stable over time (range: 1-24 months), while the review of Brownson et al. (1997) indicated that there might be reductions in the size of the effect over time. The relatively small effect sizes found in the present study may be due to the very short measurement period (one month). Another reason why the effect of the ban was relatively small is related to limitations of the workplacesmoking ban in the Netherlands. Not only were employees in 


\section{Nicotine \& Tobacco Research, Volume 13, Number 6 (June 2011)}

restaurants, pubs, bars, and discotheques excluded from this ban, but employers were also permitted to offer designated smoking rooms at work, thereby reducing the potential effect of the workplace-smoking ban on the total tobacco consumption and smoking cessation (Fichtenberg \& Glantz, 2002; Levy et al., 2004 ).

The effect of tax increases among employees in our study is somewhat larger than in most other studies. This is perhaps best clarified by comparing the price elasticity in our study, based on the combined effect of the ban and tax increases, with that of other studies. We estimate a $16.3 \%$ decrease in total tobacco consumption (prevalence and number of cigarettes of smokers) per $24 \%$ tax increase, which corresponds to a $6.8 \%$ decrease in consumption per $10 \%$ price increase. Review studies have indicated that a $10 \%$ increase in tobacco product prices results in a $4 \%$ (Fichtenberg \& Glantz, 2002), 4.1\% (Hopkins et al., 2001), 3\%5\% (Levy et al., 2004), or 4.3\% (Gallus, Schiaffino, La Vecchia, Townsend, \& Fernandez, 2006) decrease in tobacco consumption in the general population. In the present study, the effects of the tax increase are estimated to be higher than those found in other studies. Our interpretation is that this is largely due to the fact that the tax increases are combined with a workplace-smoking ban. Therefore, our results seem to support the conclusions from studies in the United States (Emont et al., 1993) and Canada (Stephens et al., 1997, 2001) that a combination of measures focusing on clean indoor air and price of tobacco is likely to result in greater effects than each of these measures separately.

For respondents without paid work, we did not find significant effects of the tax increases on prevalence of smoking, the number of cigarettes of smokers per day, and the proportion of quitters. The relatively small number of those without paid work implies a relatively low statistical power. In the analysis of the prevalence of smoking, the $O R$ for tax increases found for those with and without work showed hardly any difference. However, in the analysis of the number of cigarettes among smokers, it appeared that the effect of the tax increases estimated for those without work was opposite to the effect estimated for those with work. We also estimated the price elasticity among those who had no paid work and found that the tax increase of $24 \%$ was associated with a $4.4 \%$ decrease in cigarette consumption. This means a $1.8 \%$ decrease in consumption per $10 \%$ price increase. This is much lower than estimated for those with paid work $(6.8 \%)$. All in all, we think it is safe to conclude that the two tax increases had little to no effect on the tobacco consumption of those without work.

This lack of effect among those without paid work may seem in sharp contrast to studies indicating that in the lower strata, the effect of tax measures tend to be stronger (Gallus et al., 2006; Joossens \& Raw, 2006; Thomas et al., 2008; Townsend et al., 1994). However, despite that more than $50 \%$ of those without paid work have a low level education (Table 1), it would be wrong to assume that the nonworking population in the present study is homogeneous in terms of social stratification. In the present study, those without paid work represent $36 \%$ of the total population of which only $4 \%$ is unemployed and seeking work and $32 \%$ is economically inactive in very diverse ways, for example, (full-time) students, housewives, early retirement, disability pension, etc. (Statistics Netherlands, 2009). For the majority in this economically inactive group, having no paid work does not mean that they are "poor" or belong to the lower strata. Therefore, our nonworking population is possibly more heterogeneous compared with the lower strata as distinguished in other studies. Some subpopulations (e.g., those living on welfare only) may well be very responsive to tax increases, whereas other subpopulations (e.g. women with a large family income who choose not to have paid work might be less responsive to such increases.

In general, the prevalence of smoking in the category without work $(21.1 \%$ vs. $27.5 \%$ among the working) is much lower than among those with paid work. This relatively low prevalence may explain some of the lack of responsiveness to price measures.

The strength of this population-based study is the large number of respondents $(n=32,014)$, which allowed to differentiate the effect of measures among those with and without paid work. Also, by continuously measuring samples over a 3-year period, the main outcomes are less influenced by seasonal variations and indicate the effect of measures over a period of one year or longer. In addition, we could control for several variables that are relatively strongly correlated with differences in smoking.

There are also a number of limitations. One of the limitations concerns the possible lack of representativeness of the Internet sampling frame used. In the Netherlands, the proportion of people with access to Internet in 2005 is relatively high (83\%). Among those without work, Internet access is lower (66\%) than among those with paid work (90\%). However, there is very little difference in financial reasons as a cause for no Internet connection between those with (1\%) and without work (5\%; Statistics Netherlands, 2010). Although the inclusion of the nonworking in the Internet sample is less optimal than those who have paid work, there are no indications that this has led to a strong under representation among those not working of persons more responsive to tax measures. Furthermore, a study comparing estimates of substance use based on an Internet sample and a sample drawn from the general population register (covering $>98 \%$ of the inhabitants) shows that Internet samples tend to overestimate the prevalence of substance use (Spijkerman, Knibbe, Knoops, Mheen, \& Eijnden, 2009). Applied to the present study, this might mean that the proportion of daily smokers and the amount of cigarettes were overestimated. However, if the case, will probably apply both before and after implementation of the different interventions. Therefore, the change in the outcome measures is probably a valid indication of the effect of the interventions applied.

Another limitation is that we have not been able to control for substitution, for example, people selecting cheaper brands or cheaper types of cigarettes (e.g., hand rolled instead of factorymade cigarettes) and the effect of inflation. Concerning substitution, most likely, some of the smokers switched to cheaper brands/cigarettes. However, the effect of this may have been limited because the last tax increase of $4 \%$ was exclusively aimed at increasing the minimum price of the cheaper brands and cigarettes. Concerning the effect of inflation, the effect sizes of the tax increases might have been smaller had we been able to control for inflation. However, in the Netherlands, the price increases of cigarettes exceed the level of inflation, implying that at least some effects of the tax increases could have been expected.

Finally, we like to emphasize that the very short period of one month in which the workplace-smoking ban was in force as only measure limits the possibility to examine the effect of this 
measure among respondents with paid work. The effects we found among those with paid work in the long run are probably the combined effect of the workplace-smoking ban and tax increases.

\section{Funding}

This work was supported by the Food and Consumer Product Safety Authority.

\section{Declaration of Interests}

None declared.

\section{Acknowledgments}

The authors thank the Dutch Expertise Centre on Tobacco Control (STIVORO) for allowing use of their data for this study.

\section{References}

Brownson, R. C., Eriksen, M. P., Davis, R. M., \& Warner, K. E. (1997). Environmental tobacco smoke: Health effects and policies to reduce exposure. Annual Review of Public Health, 18, 163-185. doi:10.1146/annurev.publhealth.18.1.163

Chapman, S., Borland, R., Scollo, M., Brownson, R. C., Dominello, A., \& Woodward, S. (1999). The impact of smokefree workplaces on declining cigarette consumption in Australia and the United States. American Journal of Public Health, 89, 1018-1023. (Accession No. 2009957)

Emont, S. L., Choi, W. S., Novotny, T. E., \& Giovino, G. A. (1993). Clean indoor air legislation, taxation, and smoking behaviour in the United States: An ecological analysis. Tobacco Control, 2, 13-17. doi:10.1136/tc.2.1.13

Evans, W. N., Farrelly, M. C., \& Montgomery, E. (1999). Do workplace smoking bans reduce smoking? American Economic Review, 89, 728-747. (Accession No. 2344891)

Farrelly, M. C., Evans, W. N., \& Sfekas, A. E. (1999). The impact of workplace smoking bans: Results from a national survey. Tobacco Control, 8, 272-277. doi:10.1136/tc.8.3.272

Fichtenberg, C. M., \& Glantz, S. A. (2002). Effect of smoke-free workplaces on smoking behaviour: Systematic review. British Medical Journal, 325, 188-194. doi:10.1136/bmj.325.7357.188

Gallus, S., Schiaffino, A., La Vecchia, C., Townsend, J., \& Fernandez, E. (2006). Price and cigarette consumption in Europe. Tobacco Control, 15, 114-119. doi:10.1136/tc.2005.012468

Guindon, G. E., Tobin, S., \& Yach, D. (2002). Trends and affordability of cigarette prices: Ample room for tax increases and related health gains. Tobacco Control, 1, 35-43. doi:10.1136/ tc.11.1.35

Heloma, A., \& Jaakkola, M. S. (2003). Four-year follow-up of smoke exposure, attitudes and smoking behaviour following enactment of Finland's national smoke-free work-place law. Addiction, 98, 1111-1117.doi:10.1046/j.1360-0443.2003.00429.x

Hopkins, D. P., Briss, P. A., Ricard, C. J., Husten, C. G., Carande-Kulis, V. G., Fielding, J. E., et al. (2001). Reviews of evidence regarding interventions to reduce tobacco use and exposure to environmental tobacco smoke. American Journal of Preventive Medicine, 20(2 Suppl.), 16-66. doi:10.1016/S07493797(00)00297-X

International Agency for Research on Cancer. (2009). IARC handbooks of cancer prevention tobacco control. Evaluating the effectiveness of smoke-free policies. Vol. 13. Lyon, France: International Agency for Research on Cancer World Health Organization.

Joossens, L., \& Raw, M. (2006). The Tobacco Control Scale: A new scale to measure country activity. Tobacco Control, 15, 247253. doi:10.1136/tc.2005.015347

Levy, D. T., Chaloupka, F., \& Gitchell, J. (2004). The effects of tobacco control policies on smoking rates: A tobacco control scorecard. Journal of Public Health Management and Practice, 10, 338353. (Accession No. 00124784 200407000-00011)

Levy, D. T., Romano, E., \& Mumford, E. (2005). The relationship of smoking cessation to sociodemographic characteristics, smoking intensity, and tobacco control policies. Nicotine \& Tobacco Research, 7, 387-396. doi:10.1080/14622200500125443

Pierce, J. P., \& León, M. (2008). Effectiveness of smoke-free policies. Lancet Oncology, 9, 614-615. doi:10.1016/S14702045(08)70167-0

Spijkerman, R., Knibbe, R., Knoops, K., Mheen, v d D., \& Eijnden, v d R. (2009). The utility of online panel surveys versus computer-assisted interviews in obtaining substance-use prevalence estimates in the Netherlands. Addiction, 104, 1641-1645. doi:10.1111/j.1360-0443.2009.02642.x

Stephens, T., Pederson, L. L., Koval, J. J., \& Kim, C. (1997). The relationship of cigarette prices and no-smoking bylaws to the prevalence of smoking in Canada. American Journal of Public Health, 87, 1519-1521. (Accession No. 9710250213)

Stephens, T., Pederson, L. L., Koval, J. J., \& Macnab, J. (2001). Comprehensive tobacco control policies and the smoking behaviour of Canadian adults. Tobacco Control, 10, 317-322. doi:10.1136/tc.10.4.317

Thomas, S., Fayter, D., Misso, K., Ogilvie, D., Petticrew, M., Sowden, A., et al. (2008). Population tobacco control interventions and their effects on social inequalities in smoking: Systematic review. Tobacco Control, 17, 230-237. doi:10.1136/tc.2007.023911

Townsend, J., Roderick, P., \& Cooper, J. (1994). Cigarette smoking by socioeconomic group, sex, and age: Effects of price, income, and health publicity. British Medical Journal, 309, 6959, 923-927.

Statistics Netherlands (2010). ICT gebruik van personen naar persoonskenmerken "ICT use of persons related to personal characteristics", Retrieved from www.cbs.nl

Statistics Netherlands (2009). Statline, Retrieved from http://statline.cbs.nl/statweb/ 